\title{
Non-linear dependency between spiking response and gamma-band power of local field potentials in the human auditory cortex
}

\author{
Hiroyuki Oya", Kirill V Nourski, Ariane E Rhone, Hiroto Kawasaki, Matthew A Howard III \\ From Twenty Second Annual Computational Neuroscience Meeting: CNS*2013 \\ Paris, France. 13-18 July 2013
}

Recent advancement in recordings of extracellular potentials from multiple sites in the human brain [1] has allowed us to simultaneously record spiking activity and local field potentials (LFP) to examine the brain's response to experimental stimuli. Various mechanisms have been suggested for the generation of the LFP. A point of special interest is that LFP reflects not only the inputs to the tissue, but also local processing. For example, spike contribution to the high-frequency LFP through increased spike rate or increased synchrony has been suggested [2]
Subjects $(\mathrm{n}=19)$ were epilepsy patients who needed intracranial electrode implantation and chronic monitoring of for diagnostic and treatment purposes. Protocols were approved by University of Iowa IRB. Recordings were made from micro contacts implanted in the Heschl's gyri during pure tone presentations. Single-trial gamma-band responses were extracted using band-pass filters (40-150 $\mathrm{Hz}$ ). Spike trains at the same contacts were analyzed with Poisson generalized linear models (GLM) with coded stimulus convolved with finite impulse-response (FIR)

$$
\begin{aligned}
& \text { Model: } \\
& \begin{array}{r}
Y[n]=H 0+\sum_{m=0}^{K} H 1[m] X[n-m]+\sum_{r=0}^{K} \sum_{s=0}^{K} H 2[r, s] X[n-r] X[n-s] \\
\text { outputs }=[\text { baseline }]+[\text { linear convolution }]+[2 \text { nd order interaction }] \\
H 1: \text { st order kernel } \quad H 2: 2 \text { nd order kernel }
\end{array}
\end{aligned}
$$

A
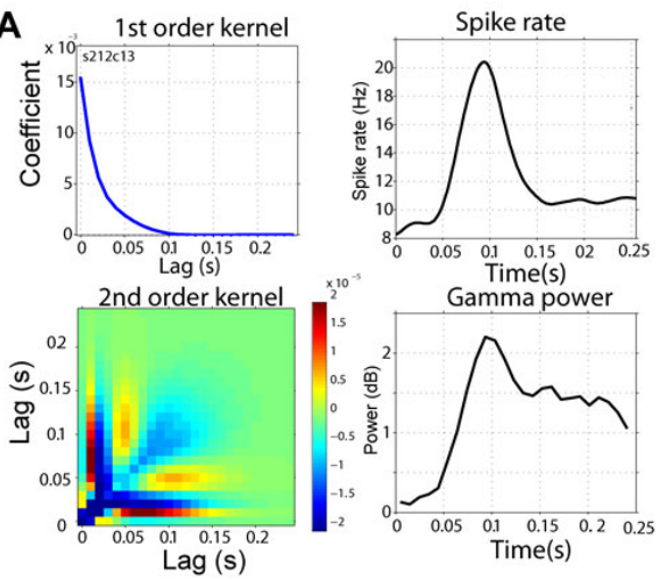

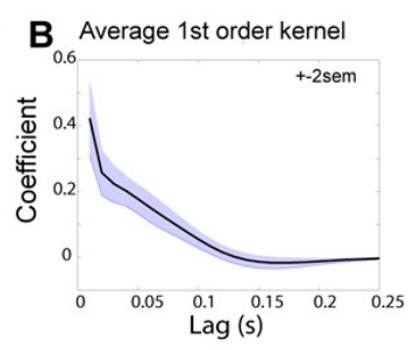

Linear and full model responses

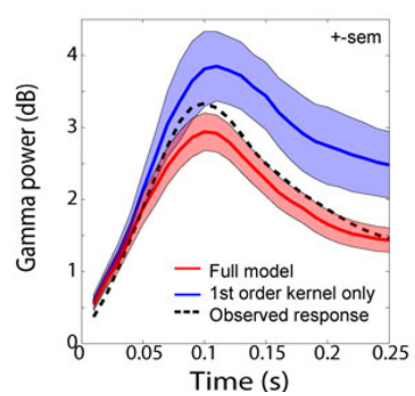

C Correlation between gamma LFP power and spike count $(0-200 \mathrm{~ms})$

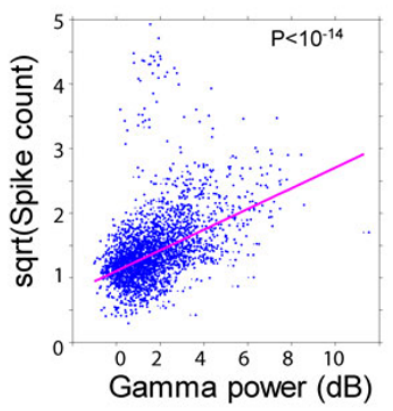

Figure 1

\footnotetext{
* Correspondence: hiroyuki-oya@uiowa.edu

Department of Neurosurgery, University of lowa, lowa City, IA, 52242, USA
}

(c) 2013 Oya et al; licensee BioMed Central Ltd. This is an Open Access article distributed under the terms of the Creative Commons 
function which was estimated from the data, as well as spiking history (up to $80 \mathrm{~ms}$ duration, determined by minimum BIC criterion) as covariates. We treated the system as a time-invariant black box and the relationship between spiking activity (rates) and gamma-band LFP power was analyzed with Volterra kernel expansion (memory length of $200 \mathrm{~ms}$ ) up to the second-order to examine potentially non-linear dependencies [3] (Figure 1A). Estimated discharge rates were used as the inputs and gamma LFP power was used as the outputs of the system. Weighted least-squares support-vector machines were utilized for estimating the regression coefficients [4], and the kernels were expanded using Laguerre orthogonal basis. First order kernel (linear filter) typically decreased toward zero within $150 \mathrm{~ms}$ lag time (Figure 1A and 1B), and $2^{\text {nd }}$-order kernels typically contain negative components, indicating non-linear suppressive effect on the gamma. (Figure 1B). A separate correlation analysis between spike count and gamma-band power within post-stimulus $200 \mathrm{~ms}$ shows strong positive correlation (Figure 1C).

\section{Conclusions}

Gamma-band LFP power correlates with spiking activity in human auditory cortex. Although, the detailed time course of gamma-band LFP cannot be explained by linear filtering of the spiking activity. A higher-order no-linear relationship between the two is suggested.

Published: 8 July 2013

\section{References}

1. Howard III MA, Volkov IO, Abbas PJ, Damasio H, Ollendieck MC, Granner MA: A chronic microelectrode investigation of the tonotopic organization of human auditory cortex. Brain Res 1996, , 724: 260-264.

2. Buzsaki G, Anastassiou CA, Koch C: The origin of extracellular fields and currents. EEG, ECoG, LFP and spikes. Nat Rev Neurosci 2012, , 13: 407-420.

3. Franz MO, Scholkopf B: A Unifying View of Wiener and Volterra Theory and Polynomial Kernel Regression. Neural Comput 2006, , 18: 3097-3118.

4. Suykens JAK, De Brabanter J, Lukas L, Vandewalle J: Weighted least squares support vector machines: robustness and sparse approximation. Neurocomputing 2002, , 48: 85-105.

doi:10.1186/1471-2202-14-S1-P175

Cite this article as: Oya et al:: Non-linear dependency between spiking response and gamma-band power of local field potentials in the human auditory cortex. BMC Neuroscience 2013 14(Suppl 1):P175.

\section{Submit your next manuscript to BioMed Central} and take full advantage of:

- Convenient online submission

- Thorough peer review

- No space constraints or color figure charges

- Immediate publication on acceptance

- Inclusion in PubMed, CAS, Scopus and Google Scholar

- Research which is freely available for redistribution

Submit your manuscript at www.biomedcentral.com/submit 